\title{
Pyrene-Containing ortho-Oligo(phenylene)ethynylene Foldamer as a Ratiometric Probe Based on Circularly Polarized Luminescence
}

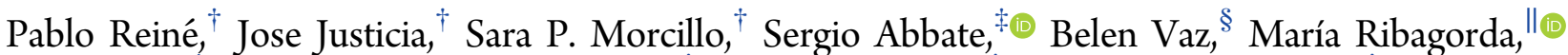 \\ Ángel Orte ${ }^{\perp}$ Luis Álvarez de Cienfuegos, ${ }^{\dagger}$ Giovanna Longhi, ${ }^{\ddagger}$ Araceli G. Campaña, ${ }^{\dagger}{ }^{\oplus}$ Delia Miguel,,,$\perp$ \\ and Juan M. Cuerva* ${ }^{* \dagger}$ \\ ${ }^{\dagger}$ Department of Organic Chemistry, University of Granada, Avenida de la Fuente Nueva, 18071 Granada, Spain \\ ${ }^{\ddagger}$ Dipartimento di Medicina Molecolare e Traslazionale, Universitá di Brescia, Viale Europa 11, 25123 Brescia, Italy \\ ${ }^{\S}$ Department of Organic Chemistry, Biomedical Research Center (CINBIO), and Southern Galicia Institute of Health Research \\ (IISSG), Universidade de Vigo, 36310 Vigo, Spain \\ "Department of Organic Chemistry, Universidad Autónoma de Madrid, Ciudad Universitaria de Cantoblanco, 28049 Madrid, Spain \\ ${ }^{\perp}$ Department of Physical Chemistry, University of Granada, Avenida de la Fuente Nueva, 18071 Granada, Spain
}

Supporting Information

ABSTRACT: In this manuscript, we report the first synthesis of an organic monomolecular emitter, which behaves as a circularly polarized luminescence (CPL)-based ratiometric probe. The enantiopure helical ortho-oligo(phenylene)ethynylene (o-OPE) core has been prepared by a new and efficient macrocyclization reaction. The combination of such $o$ OPE helical skeleton and a pyrene couple leads to two different CPL emission features in a single structure whose ratio linearly responds to silver(I) concentration.

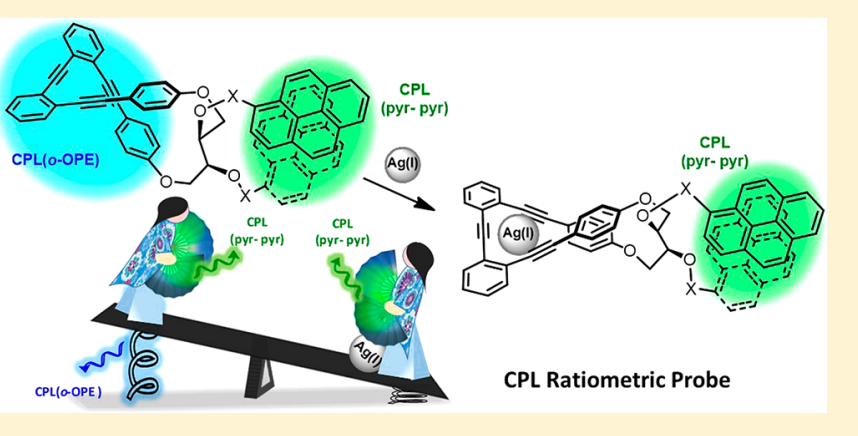

$\left.-I_{\mathrm{R}}\right), \Delta I$, as a function of the wavelength, with $I_{\mathrm{L}}$ and $I_{\mathrm{R}}$ being the intensities of the left and right circularly polarized light. The dimensionless value $g_{\text {lum }}$, defined as $2\left(I_{L}-I_{R}\right) /\left(I_{L}+I_{R}\right)$, serves to characterized the dissymmetry of the transition. Although many interesting CPL active systems have been described, the use of the CPL emission as quantitative signal in a ratiometric probe has never been demonstrated.

Therefore, we wondered if the ratiometric probe concept could be extended to CPL-active molecules. First, a hypothetical CPL probe should present two different CPL emitters in a single structure, with at least one of them being able to interact with an external stimulus and respond to it. Second, a (usually linear) relationship between the ratio of their chiroptical responses and the analyte concentration is also required. The combination of both requirements in a single structure is highly challenging since the very limited ability of CPL emitters to interact with different species. ${ }^{4}$ Noteworthy, CPL spectroscopy provides another level of resolution compared with the unpolarized emission spectrum. Thus, for example, two peaks may overlap in the total emission spectrum, but the electronic transitions involved may have opposite rotational strengths and, therefore, could be clearly distinguished in the CPL spectrum.

Received: January 18, 2018

Published: March 26, 2018 
- Concept of a hypothetical CPL Ratiometric Probe

0-OPEs: CPL switches
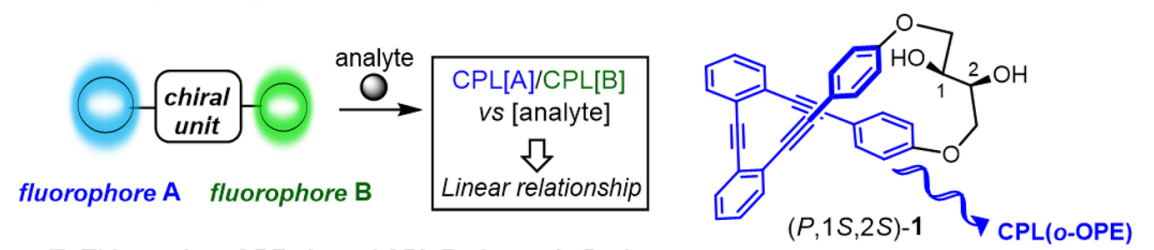

- This work: o-OPEs based CPL Ratiometric Probe

$(P, 1 S, 2 S)-1$
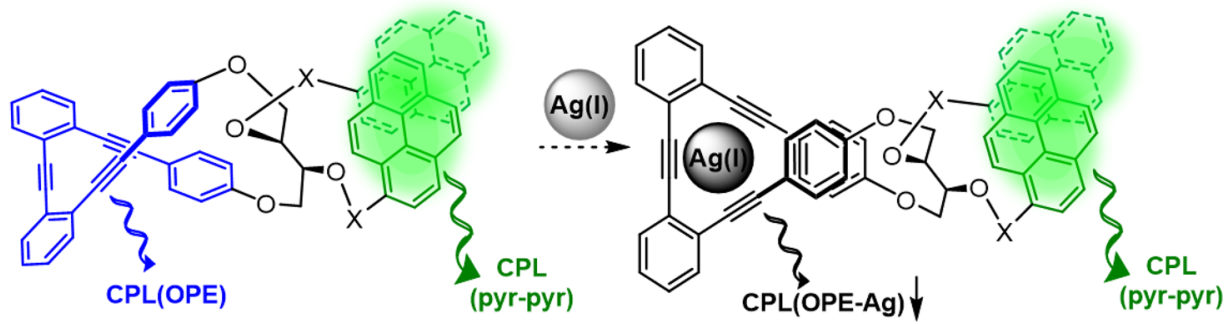

$(P, 1 S, 2 S)-2, X=-\mathrm{CH}_{2}-$

$(P, 1 \mathrm{~S}, 2 \mathrm{~S})-3, \mathrm{X}=-\mathrm{CO}-$

$(P, 1 S, 2 S)-\mathbf{2}: \mathbf{A g}, \mathrm{X}=-\mathrm{CH}_{2}-$

$(P, 1 S, 2 S)-3: A g, X=-C O-$

Figure 1. Working hypothesis of a CPL-based ratiometric probe based on $(P, 1 S, 2 S)-\mathbf{1}$.

Scheme 1. Enantioespecific Synthesis of $(P, 1 S, 2 S)-2$ and $(P, 1 S, 2 S)-3^{a}$

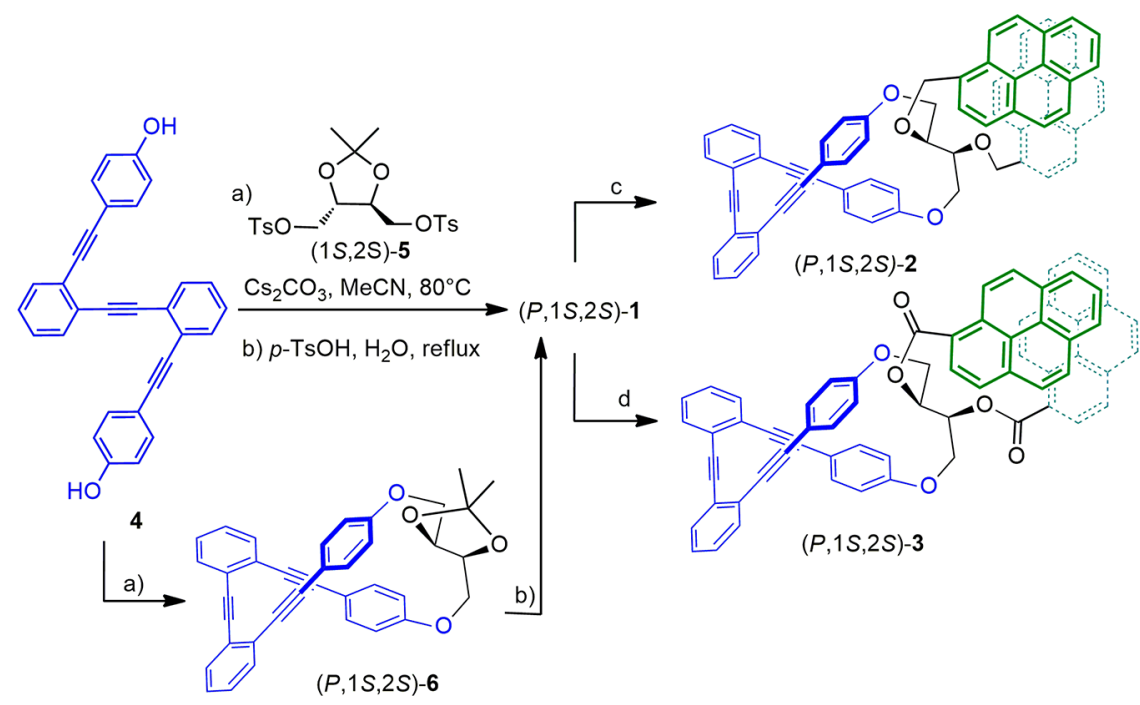

${ }^{a}$ Reaction conditions: (a) $(1 S, 2 S)-5, \mathrm{Cs}_{2} \mathrm{CO}_{3}, \mathrm{MeCN}, 80{ }^{\circ} \mathrm{C}, 22 \mathrm{~h}, 77 \%$; (b) $p$-TsOH, EtOH/ $\mathrm{H}_{2} \mathrm{O}$, reflux, 85\%; (c) 1-chloromethylpyrene, $\mathrm{NaH}$, DMF, rt, 12 h, 58\%; (d) 1-pyrenecarboxylic acid, DCC, DMAP, rt, 24 h, $85 \%$.

Within this context, we have recently described a new family of easy-to-tune CPL emitters based on stapled ortho-oligo(phenylene)ethynylenes (o-OPEs), presenting C2 symmetry $((P, 1 S, 2 S)-1$, Figure 1$)$, which showed $g_{\text {lum }}$ values up to $10^{-2}$, one of the highest values described for an organic molecule. ${ }^{5}$ Besides, they act as a CPL switch based on carbophilic interactions with $\mathrm{Ag}(\mathrm{I})$ cations. ${ }^{5}$ Interestingly, the pyrene functionalization of the $\mathrm{C} 1$ and $\mathrm{C} 2$ stereogenic carbons might result in a second CPL emitter unit in the same structure, and therefore a ratio between both chiroptical responses is expected (Figure 1). Moreover, this CPL ratio could be related to the concentration of $\operatorname{Ag}(\mathrm{I})$ cations due to their interaction with the $o$-OPE moiety. Considering this hypothesis, we have synthesized enantiopure $(P, 1 S, 2 S)-\mathbf{2}$ and $(P, 1 S, 2 S)-3$ (Figure 1) giving rise to the first ratiometric probe based on CPL, a step beyond a simple switch between two structures. A new enantioespecific synthetic strategy to obtain these helical structures with an intense CPL emission has also been developed, widening the possibility of future exploration of the chemical space of these enantiopure helical compounds by incorporating new functionalities.

\section{RESULTS AND DISCUSSION}

Although our previously reported approach toward enantiopure stapled o-OPEs was straightforward, the key stereochemical control was completed by a final chiral HPLC resolution, which is not possible in all cases. On route to $(P, 1 S, 2 S)-2$ and $(P, 1 S, 2 S)-3$, we then decided to develop a more versatile convergent approach using a macrocyclization reaction of known bisphenol 4 and a commercially available chiral ditosylate $\mathbf{5}$ (Scheme 1). ${ }^{6}$ With this strategy, both enantiomers $(P, 1 S, 2 S)-1$ and $(M, 1 R, 2 R)-1$ are now easily available at a large scale from the corresponding $(1 S, 2 S) /(1 R, 2 R)-5$. In this work, we focused our attention in $(P, 1 S, 2 S)-1$, which was further 

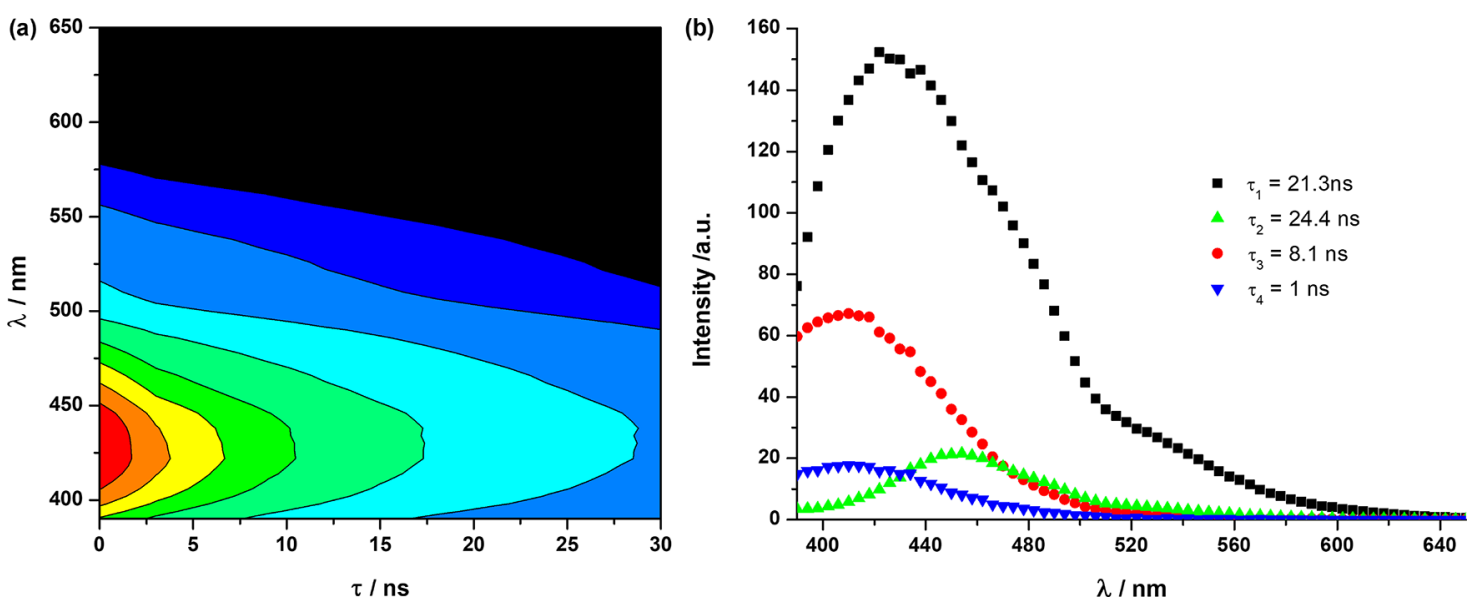

Figure 2. (a) TRES spectra of $(P, 1 S, 2 S)$-2 after a $\delta$-pulse excitation as a function of time and emission wavelength in $\mathrm{CH}_{2} \mathrm{Cl}_{2}$ as a solvent. $(\mathrm{b})$ SAEMS spectra of compound $(P, 1 S, 2 S)-2$ in $\mathrm{CH}_{2} \mathrm{Cl}_{2}$ as a solvent.
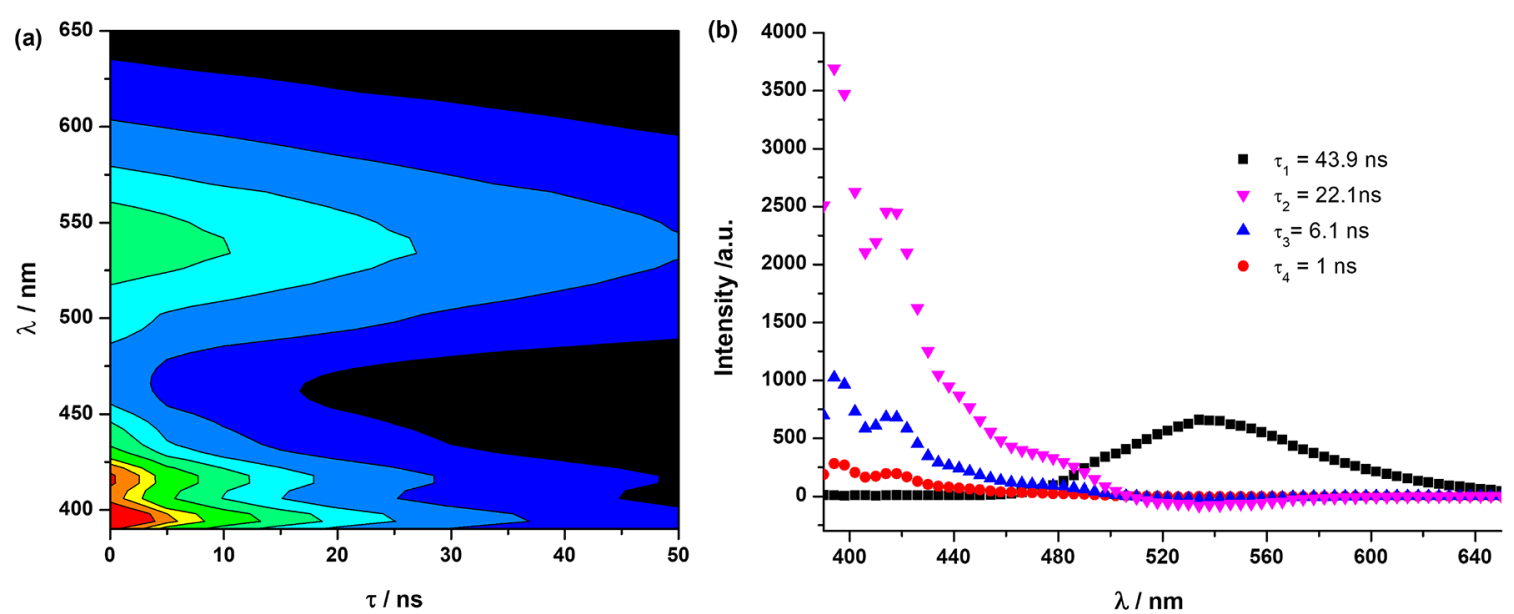

Figure 3. (a) TRES spectra of $(P, 1 S, 2 S)-3$ after a $\delta$-pulse excitation as a function of time and emission wavelength in $\mathrm{CH}_{2} \mathrm{Cl}_{2}$ as a solvent. $(\mathrm{b})$ SAEMS spectra of compound $(P, 1 S, 2 S)-3$ in $\mathrm{CH}_{2} \mathrm{Cl}_{2}$ as a solvent.

functionalized using 1-chloromethylpyrene and 1-pyrenecarboxylic acid to yield enantiopure $(P, 1 S, 2 S)-2$ and $(P, 1 S, 2 S)-3$ in good yields.

In these systems, the $P / M$ helical chirality is controlled by the chirality of the oxygenated tether. Therefore, the flexibility of the macrocyclic backbone allows a "biased" equilibrium between $P$ and $M$ configurations. In the case of a $(S, S)$-diol, the observed helicity is $P$. A total bias of such equilibrium is desired in order to maximize the chiroptical responses as they mainly depend on the helix. An exploration of this effect in simple derivatives led us to conclude that the very robust $g_{\text {lum }}$ value around $10^{-2}$ of $(P, 1 S, 2 S)-1$ was retained and was independent of any substitution in the diol. ${ }^{7}$ This observed relationship between the helix and the tether suggests that they were stereochemically coupled. That is, strong variations of the OPE helicity could, in principle, affect the spatial arrangement of a pyrene-functionalized tether and vice versa. The controlled translation of this dynamism into chiroptical properties could result in a ratiometric probe. In this case, the anticipated interaction of $\mathrm{Ag}(\mathrm{I})$ cation with the OPE will probably be the driving force for the change in the spatial arrangement of the whole molecule.

To this end, we prepared the alkyl- $(P, 1 S, 2 S)-2$ and acyl$(P, 1 S, 2 S)-3$ derivatives (Scheme 1). In this case, the pyrene moieties included in the oxygenated tether can interact with each other, resulting in interesting photophysical properties. ${ }^{8}$ Remarkably, such optical responses are transported to chiroptical properties (CD and CPL signals) once the environment is chiral. ${ }^{9}$

Compounds $(P, 1 S, 2 S)-2$ and $(P, 1 S, 2 S)-3$ are fluorescent with solvent dependent quantum yields ( $\mathrm{QY}$ ) going from 0.14 to 0.55 and from 0.18 to 0.44 , respectively (Table S1). When exciting at $350 \mathrm{~nm}$, the emission is controlled by two main contributions: one broad emission band around $410 \mathrm{~nm}$, where the emission from both the helix and monomer pyrene appears overlapped, and other one corresponding to the pyrene excimer (a broad unstructured band centered around 520-540 nm) (Figure S4). The relative contribution of these bands is highly dependent on the solvent. (See Figures S5 and S6.) The presence of a pyrene excimer band confirmed the close proximity of the two pyrene units, for an intramolecular excited-state interaction. Time-resolved emission spectroscopy (TRES) allowed following the time evolution of the spectral profiles. For $(P, 1 S, 2 S)-\mathbf{2}$, a red shift of the emission maximum in the first $15 \mathrm{~ns}$ of decay indicates a slow solvent reorganization upon excitation (Figure 2a and Figure S7). This is consistent with the slow dynamics of the helix and the large size of the molecule. The species-associated emission spectra (SAEMS) allowed differentiating three species with lifetimes of $1,8.1$, and $21.3 \mathrm{~ns}$, showing the solvent relaxation- 


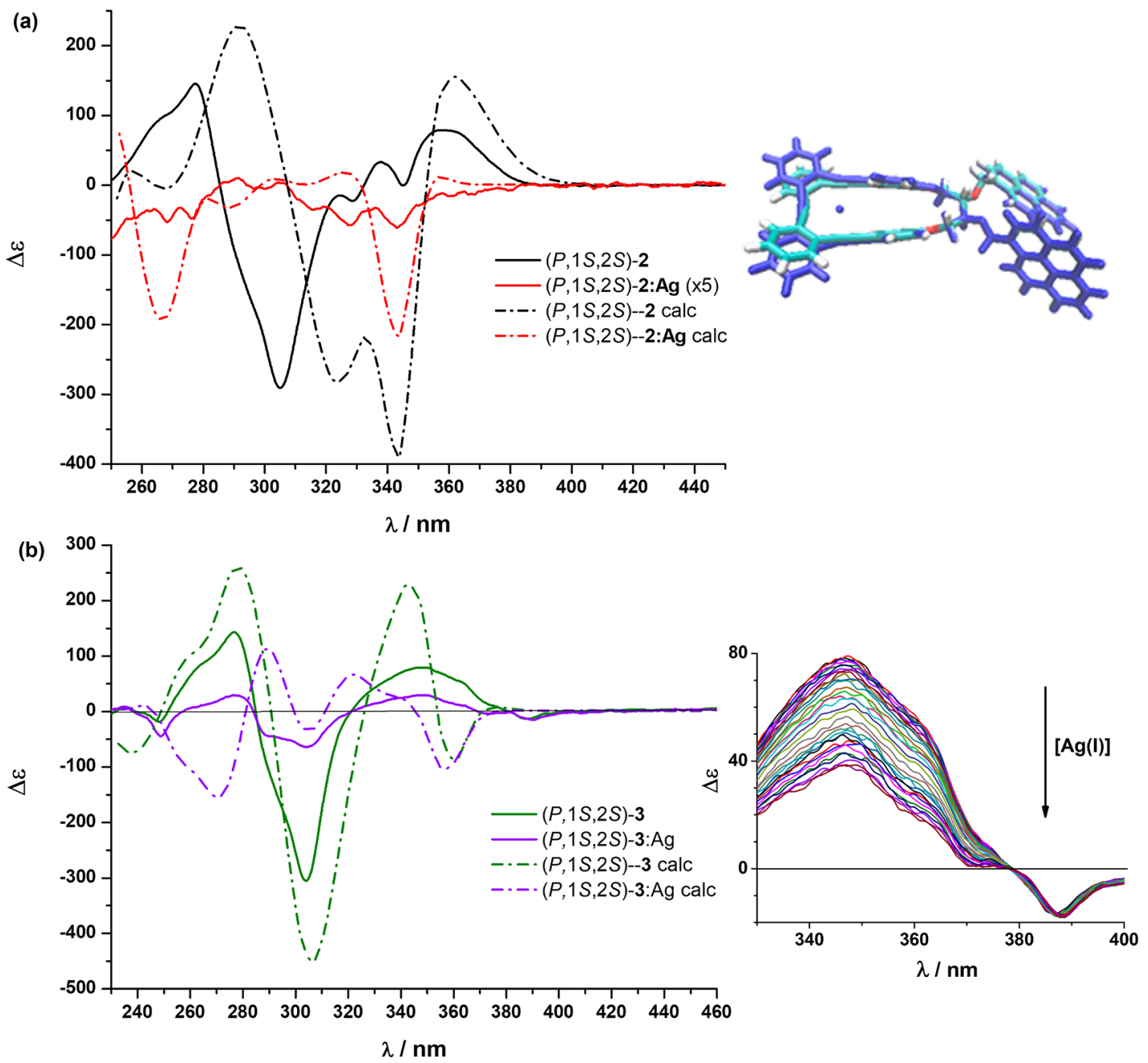

Figure 4. (a) Left: experimental (solid line) and average of the main calculated (dash-dotted line) CD spectra of compound (P,1S,2S)-2 in the absence (black) and presence (red) of $\mathrm{Ag}(\mathrm{I})$. Experimental intensity of the silver complex has been multiplied by 5 . Right: calculated main conformer of $(P, 1 S, 2 S)-2$ in the absence (light blue) and presence (blue) of $\mathrm{Ag}(\mathrm{I})$. (b) Left: experimental (solid line) and average of the main calculated (dashdotted line) $\mathrm{CD}$ spectra of compound $(P, 1 S, 2 S)-3$ in the absence (green) and presence (violet) of $\mathrm{Ag}(\mathrm{I})$. Right: CD titration of compound $(P, 1 S, 2 S)-3$. Offsets of $15 \mathrm{~nm}$ have been applied to theoretical data.

mediated red shift in the emission maximum, and the latter exhibiting the pyrene excimer emission between 510 and 650 $\mathrm{nm}$. A fourth species, with a lifetime of $24.4 \mathrm{~ns}$ exhibited a maximum at $450 \mathrm{~nm}$ with a typical structure of the helix emission (Figure 2b). This lifetime was longer than the one previously described for this kind of helices due to the pyrenes excimer contribution to the main transitions.

More interesting results were obtained for $(P, 1 S, 2 S)-3$, which presents features of excited-state dynamics as the emission of the pyrene excimer is formed from other species (Figures 3a and S5). The spectral decomposition (SAEMS, Figure 3b) showed three species with the typical emission of pyrenes and lifetimes of 1.0, 6.1, and 22.1 ns. These species exhibited negative contributions in the pyrene excimer region, clearly supporting that the excimer emission (fourth species with a lifetime of $43.9 \mathrm{~ns}$ ) builds up from the others through an excited-state reaction. The $o$-OPE emission appears as a shoulder overlapping the pyrene excimer species of a $22.1 \mathrm{~ns}$ lifetime.

Circular dichroism (CD) spectra of $(P, 1 S, 2 S)-2$ and $(P, 1 S, 2 S)$-3 were also recorded (Figure 4$)$. For $(P, 1 S, 2 S)-\mathbf{2}$, overlapped absorption signals corresponding to the absorption of the $o$-OPE (at $345 \mathrm{~nm}$ ) and pyrene subunits (at $365 \mathrm{~nm}$ ) could be clearly observed. Remarkably, the opposite signs allowed us to discern between the contributions of each substructure throughout the entire spectra, which might be very relevant for a potential chiroptical ratiometric probe, as we commented before. In the case of $(P, 1 S, 2 S)-3$, the presence of the carbonyl group red shifts the absorption of the pyrenes and their CD signals were partially resolved $(\lambda=387 \mathrm{~nm})$.

The CD spectra of $(P, 1 S, 2 S)-2$ in the presence of $\mathrm{Ag}(\mathrm{I})$ showed a decrease in the $\mathrm{CD}$ intensity as $\mathrm{Ag}(\mathrm{I})$ concentration increased (Figure $4 \mathrm{a}$ and Figures S9 and S10). This phenomenon, already described by us, ${ }^{5 a}$ is due to the planar arrangement of the OPE alkynes to accommodate the cation in nonpolar solvents. ${ }^{10,11}$

The same behavior is observed for $(P, 1 S, 2 S)-3$ silver coordination, causing again the disappearance of the OPE helicity due to the planarization of the structure and the corresponding CD signal disappearance $(345 \mathrm{~nm}$ ) (Figure $4 \mathrm{~b}$ and Figures S11-S13). However, such a strong structural change affected to a much lesser extent the chiral environment of the pyrenes, remaining the corresponding CD signal (387 $\mathrm{nm}$ ) (Figure $4 \mathrm{~b}$, right). This result supports the idea that the 

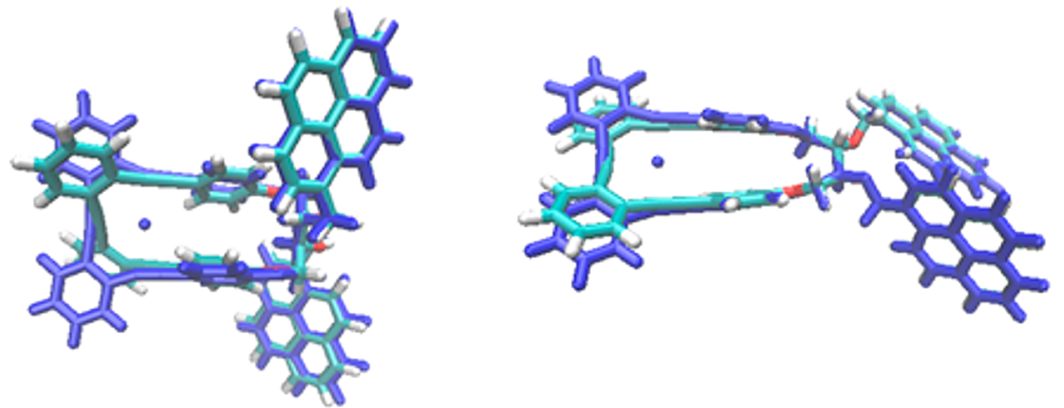

Figure 5. (a) Calculated first two conformers of $(P, 1 S, 2 S)-2$ in the absence (light blue) and presence (blue) of $\mathrm{Ag}(\mathrm{I})$.
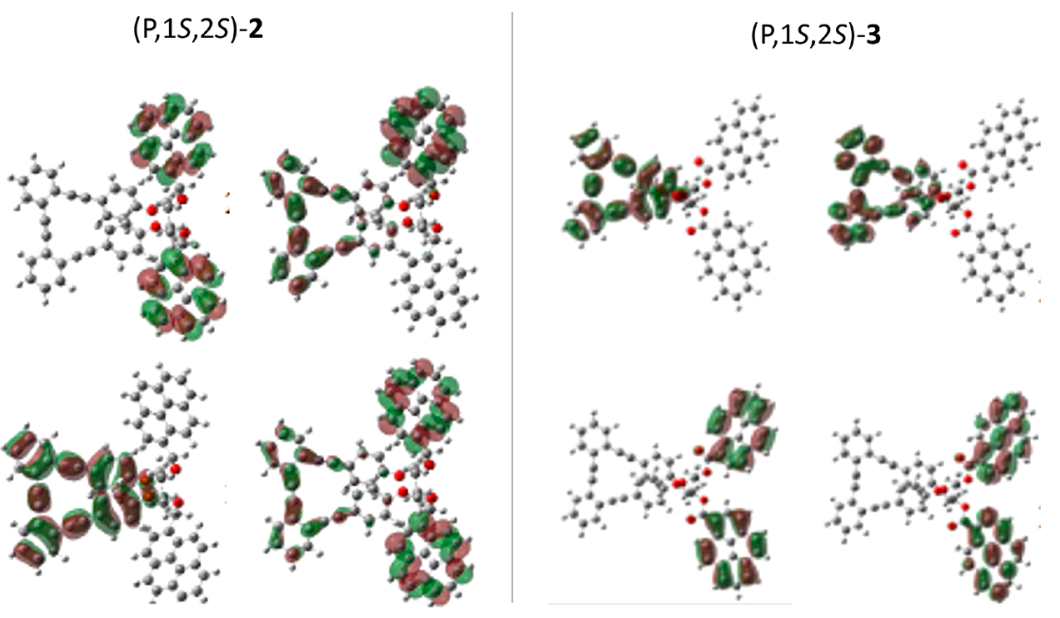

Figure 6. Examples of different orbitals of the main conformer of $(P, 1 S, 2 S)-2$ (left) and $(P, 1 S, 2 S)-3$ (right) in the absence of $\mathrm{Ag}(\mathrm{I})$.

geometry of the two subunits may be independent in the ground state, and therefore, $(P, 1 S, 2 S)-3$ could be used as a $\mathrm{Ag}(\mathrm{I})$ ratiometric probe based on $\mathrm{CD}$. In fact, a good linear relationship $\left(R^{2}=0.96\right)$ was obtained between the ratio of $\Delta \varepsilon$ intensities at 345 and $387 \mathrm{~nm}$ and $\mathrm{Ag}(\mathrm{I})$ concentration. (See the inset in Figures $4 \mathrm{~b}$ and $\mathrm{S} 12$ for more details.) Fitting of $\Delta \varepsilon$ value at $345 \mathrm{~nm}$ at different silver concentrations gives a binding constant of $K_{(P, S, S)-3}=6360 \pm 5 \% \mathrm{M}^{-1}$.

To gain some insights into these different behaviors, we performed theoretical calculations at the DFT level. In all of the cases, the calculated $\mathrm{CD}$ spectra reproduced the experimental sign taking into account the chiral synthon used. For $(P, 1 S, 2 S)$ 2 , several conformers were analyzed, and a majority of $P$ conformations of the OPE moiety was obtained (a total of $77 \%$ of population). Moreover, among the conformers with the same helicity, differences were only found in the pyrene orientation and not in the shape of the OPE backbone. (See the Supporting Information for details.) In all of the cases, the interaction with $\operatorname{Ag}(\mathrm{I})$ changes the shape of the OPE, which lost the helicoidal shape as was previously described for analogous $p, p$-substituted compounds (Figure 5). ${ }^{10}$

Considering the orbitals involved in the first principal transition for major conformers in the absence of $\operatorname{Ag}(\mathrm{I})$, a main difference can be observed between compounds $(P, 1 S, 2 S)-2$ and 3. Alkyl derivative $(P, 1 S, 2 S)-2$ presents orbitals localized just on the pyrene rings, just on the OPE backbone, and some delocalized on the whole molecule. However, for compound $(P, 1 S, 2 S)-3$, there is a clear separation between pyrene and OPE moieties (Figure 6).

The rotational strengths of different conformers and the orbitals involved in the first main transitions were also analyzed to assign the observed features to either the OPE or the pyrene chromophore. (See the Supporting Information for details.) In this sense, a good agreement between experimental and theory both in absorption and CD spectra was observed. As it can be seen in Figure 4a, the calculated CD response reproduces quite satisfactorily the observed spectra and also their variations upon silver addition; only the intensity of the narrow bands attributed to pyrene are overestimated by calculations. The same kind of calculations were carried out for compound $(P, 1 S, 2 S)-3$. As was previously mentioned, the main observed difference is related with the orbitals responsible for the main transitions in the absence of $\mathrm{Ag}(\mathrm{I})$, which are localized either in the pyrene subunit or in the OPE moiety, whereas for the ether derivative 2 there was not a clear separation between the two moieties. (See Figures S19 and S24). Again, we obtained a good fitting between calculated and experimental CD spectra (Figure $4 b)$.

CPL responses of both compounds were recorded in the absence and presence of $\operatorname{Ag}(\mathrm{I}) .(P, 1 S, 2 S)-2$ presented a differential emission with two different signals, which can be attributed to the two decoupled subunits (Figure 7a). The first one, corresponding to the OPE subunit, presented $g_{\text {lum }}$ values of $1.2 \times 10^{-2}$ at around $390 \mathrm{~nm}$ (Figure S14), as it was previously observed for diol $(P, 1 S, 2 S)-1$. The second signal, with a negative sign derived from the pyrenes, presented a $g_{\text {lum }}$ value around $-5 \times 10^{-3}$ (around $515 \mathrm{~nm}$ ). These two values can be reasonably detected by CPL equipment. Unexpectedly, $(P, 1 S, 2 S)-3$ presented a very different behavior (Figure $7 \mathrm{~b})$. In this case, the fluorescent $o$-OPE subunit showed no CPL emission, being only detectable by the response of the pyrenes excimer with a $g_{\text {lum }}$ value around $-3 \times 10^{-2}$ at $540 \mathrm{~nm}$ and +0.7 

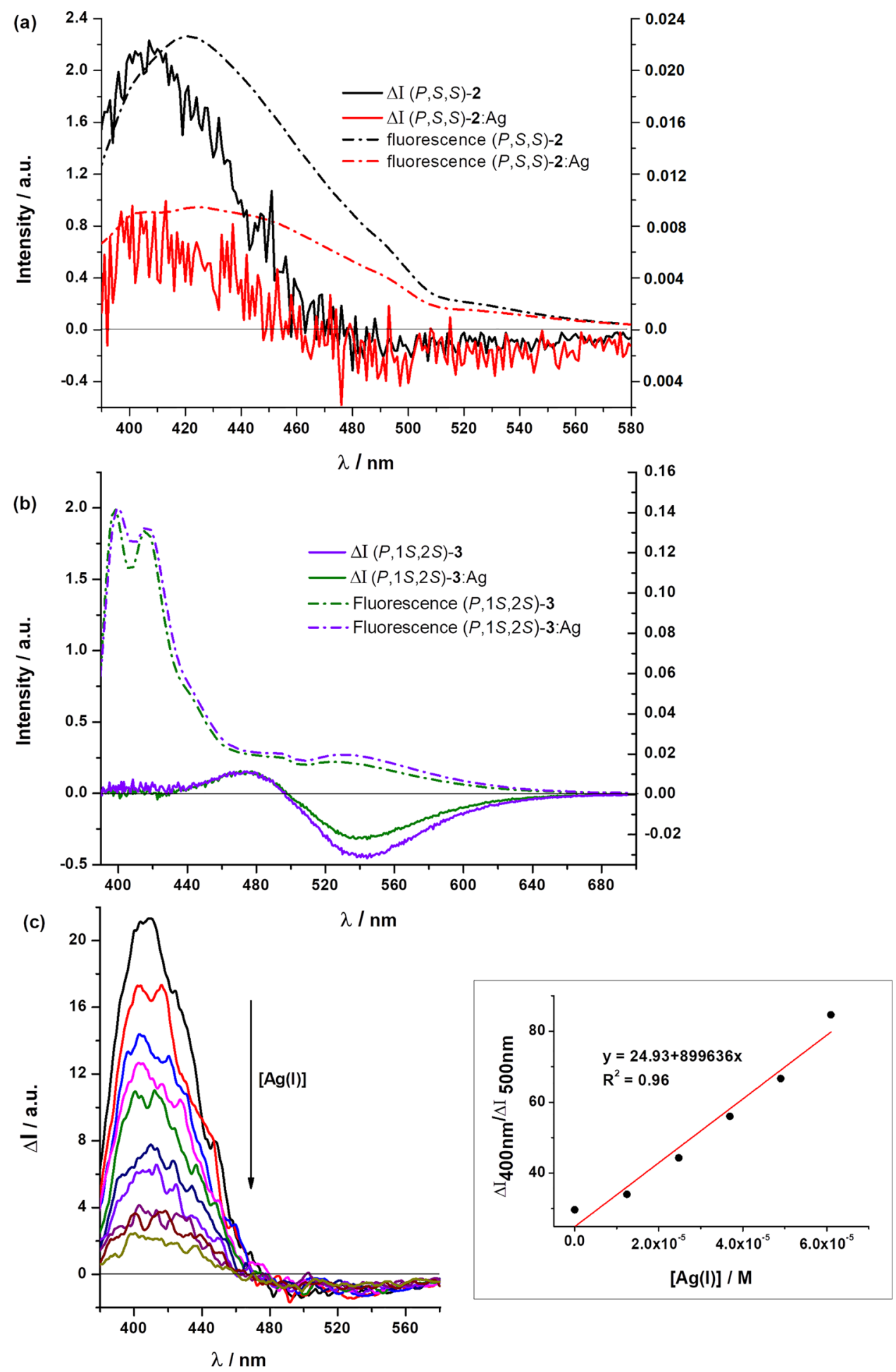

Figure 7. Fluorescence spectra (dashed line) and left-right $(\Delta I)$ intensities (solid line) of compounds (a) $(P, 1 S, 2 S)-2$ and $(\mathrm{b})(P, 1 S, 2 S)-3$. $(\Delta I$ intensities of the $\mathrm{Ag}(\mathrm{I})$ complex are referred to as right axis.) (c) CPL titration of compound $(P, 1 S, 2 S)-2$ with $\mathrm{AgBF}_{4}$. Inset: linear fitting of the ratio between left-right fluorescence intensity $(\Delta I)$ at 400 and $500 \mathrm{~nm}$ versus $\mathrm{Ag}(\mathrm{I})$ concentration.

$\times 10^{-2}$ at about $480 \mathrm{~nm}$ (Figure S14) to prevent the use of $(P, 1 S, 2 S)-3$ as a ratiometric probe based on CPL measurements. $^{9 c, f}$ This signal observed in the emissive region of the pyrene groups is a couplet. The interpretation of such couplet is not an easy task, although some explanations of the bisignated signals in CPL have been described: ${ }^{5 a, 13,14}$ one may invoke the presence of different conformers, with different geometries in their ground state and also different $S 1$ excited states, ${ }^{5 a}$ or one may find that the dominant conformer in the ground state presents a S1 state with two minima (like in camphor). ${ }^{13 a}$ Considering the TRES results and the OPE emissive bands observed in the other studied compounds containing the same moiety, both CPL features may be assigned to pyrene fluorophore with different arrangements. In any case, it seems that once the pyrene unit is excited, the excimer with the second pyrene unit, in close proximity, is formed within $1 \mathrm{~ns}$, as 
evidenced by the negative pre-exponential factor of the shortest lifetime in the fluorescence decay traces. This fast formation of the excimer and the subsequent change in geometry forced a planarization of the OPE.

Thus, we proceeded with the study of the CPL response of compound $(P, 1 S, 2 S)-2$ in the presence of $\mathrm{Ag}(\mathrm{I})$. The $\mathrm{CPL}$ response in terms of $\Delta I$ diminishes in the presence of increasing amounts of $\mathrm{Ag}(\mathrm{I})$ for both signals (Figure $7 \mathrm{c}$ ). Moreover, the different sign of the two CPL responses was ideal for the quantification. In fact, the ratio between absolute values of $\Delta I(400 \mathrm{~nm}) / \Delta I(500 \mathrm{~nm})$ showed a linear response with the $\operatorname{Ag}(\mathrm{I})$ content as required for a ratiometric probe (Figure $7 c$, inset). ${ }^{15}$

\section{CONCLUSION}

In summary, we have synthesized two compounds, each one bearing two moieties with a characteristic chiroptical and fluorescent activity. The OPE moiety structure is sensitive to $\mathrm{Ag}$; on the contrary, the pyrene reciprocal orientation appears to be preserved also in the Ag complex. We developed and demonstrated that compound $(P, 1 S, 2 S)-2$ with two CPL emissions can behave as the first example reported of a ratiometric probe based on CPL emission. Although the described example presents limitations, the expected superiority in terms of sensitivity and selectivity of CPL probes for future applications in CPL-based microscopes relies in the assumption that the translation of the usual fluorescent-based analytic techniques is possible. ${ }^{16}$ In this sense, the synthesis of novel CPL probes able to carry different functions is a prerequisite for the full development of this technique into a standard analytical technique. Development of ratiometric probes with more balanced CPL emissions and better signal-to-noise ratios is underway.

\section{EXPERIMENTAL SECTION}

General Section. All reagents were used as purchased from standard chemical suppliers and used without further purification. TLC was performed on aluminum-backed plates coated with silica gel 60 (230-240 mesh) with the F254 indicator. The spots were visualized with UV light $(254 \mathrm{~nm})$. All chromatography purifications were performed with silica gel $60(40-60 \mu \mathrm{m})$. NMR spectra were measured at room temperature. ${ }^{1} \mathrm{H}$ NMR spectra were recorded at 400 and $500 \mathrm{MHz}$. Chemical shifts are reported in ppm using the residual solvent peak as a reference $\left(\mathrm{CHCl}_{3} \delta=7.26 \mathrm{ppm}, \mathrm{CH}_{2} \mathrm{Cl}_{2} \delta=5.32\right.$ $\mathrm{ppm})$. Data are reported as follows: chemical shift, multiplicity ( $\mathrm{s}=$ singlet, $\mathrm{d}=$ doublet, $\mathrm{t}=$ triplet, $\mathrm{q}=$ quartet, quint $=$ quintuplet, $\mathrm{m}=$ multiplet, $\mathrm{dd}=$ doublet of doublets, $\mathrm{dt}=$ doublet of triplets, $\mathrm{dq}=$ doublet of quartets, $t d=$ triplet of doublets, $b s=$ broad singlet $)$, coupling constant $(\mathrm{J}$ in $\mathrm{Hz})$, and integration. ${ }^{13} \mathrm{C}$ NMR spectra were recorded at 100 and $125 \mathrm{MHz}$ using broad-band proton decoupling, and chemical shifts are reported in ppm using residual solvent peaks as a reference $\left(\mathrm{CHCl}_{3} \delta=77.16 \mathrm{ppm}, \mathrm{CH}_{2} \mathrm{Cl}_{2} \delta=54.0 \mathrm{ppm}\right)$. Carbon multiplicities were assigned by DEPT techniques. High resolution mass spectra (HRMS) were recorded on a mass spectrometer using atmospheric-pressure chemical ionization (APCI+) or electrospray ionization (ESI). Known compound $\mathbf{4}$ was isolated as a pure sample and showed NMR spectra matching those of previously reported data. $^{\text {5a }}$

Synthesis of Compound $(P, 1 \mathrm{~S}, 2 \mathrm{~S})-1$. A solution of 4 (943 mg, 2.3 $\mathrm{mmol})$ in $\mathrm{CH}_{3} \mathrm{CN}(15 \mathrm{~mL})$ was added to a mixture of 1,4 -di-O-tosyl2,3-O-isopropyl-indene-L-threitol $(S, S)-5(1.1 \mathrm{~g}, 2.3 \mathrm{mmol})^{6}$ and $\mathrm{Cs}_{2} \mathrm{CO}_{3}(1.8 \mathrm{~g}, 5.52 \mathrm{mmol})$ in $\mathrm{CH}_{3} \mathrm{CN}(135 \mathrm{~mL})$. The mixture was heated under reflux for $22 \mathrm{~h}$. Then, the solvent was removed. The residue was purified by flash chromatography (EtOAc/hexane 3:7) to give the corresponding ketal $(P, 1 S, 2 S)-6(950 \mathrm{mg}, 77 \%)$. Yellow solid, mp 165-174 ${ }^{\circ} \mathrm{C} .{ }^{1} \mathrm{H}$ NMR $\left(400 \mathrm{MHz}, \mathrm{CDCl}_{3}\right): \delta 7.66-7.61(\mathrm{~m}, 2 \mathrm{H})$,
7.60-7.56 (m, 2H), 7.35-7.28 (m, 4H), $7.24(\mathrm{~d}, J=8.7 \mathrm{~Hz}, 4 \mathrm{H}), 6.42$ $(\mathrm{d}, J=8.7 \mathrm{~Hz}, 4 \mathrm{H}), 4.39-4.22(\mathrm{~m}, 6 \mathrm{H}), 1.50(\mathrm{~s}, 6 \mathrm{H}) .{ }^{13} \mathrm{C}$ NMR $(100$ $\left.\mathrm{MHz}, \mathrm{CDCl}_{3}\right): \delta 158.2(\mathrm{C}), 133.8(\mathrm{CH}), 133.4(\mathrm{CH}), 133.1(\mathrm{CH})$, $130.1(\mathrm{C}), 128.2(\mathrm{CH}), 127.7(\mathrm{CH}), 125.3(\mathrm{C}), 124.9(\mathrm{C}), 115.9(\mathrm{C})$, $114.4(\mathrm{CH}), 109.5(\mathrm{C}), 93.8(\mathrm{C}), 92.6(\mathrm{C}), 87.5(\mathrm{C}), 75.2(\mathrm{CH}), 67.0$ $\left(\mathrm{CH}_{2}\right), 27.0\left(\mathrm{CH}_{3}\right)$. HRMS (ESI-TOF) $\mathrm{m} / z:[\mathrm{M}+\mathrm{Na}]^{+}$calcd for $\mathrm{C}_{37} \mathrm{H}_{28} \mathrm{O}_{4} \mathrm{Na}$, 559.1879; found, 559.1864.

To a solution of previously described ketal $(P, 1 S, 2 S)-6$ (295 mg, $0.55 \mathrm{mmol})$ in $\mathrm{MeOH}(25 \mathrm{~mL}), p \mathrm{TsOH}(10 \mathrm{mg}, 0.055 \mathrm{mmol})$ and water $(40 \mathrm{mg}, 2.2 \mathrm{mmol}$ ) were added. The reaction was heated under reflux for $2.5 \mathrm{~h}$. Then, the mixture was diluted with abundant $\mathrm{CH}_{2} \mathrm{Cl}_{2}$, washed with water, and dried over anhydrous $\mathrm{Na}_{2} \mathrm{SO}_{4}$, and the solvent was removed. The residue was purified by flash chromatography (EtOAc/hexane 4:6) to give diol $(P, 1 S, 2 S)-1$ (232 mg, 85\%). Its ${ }^{1} \mathrm{H}$ and ${ }^{13} \mathrm{C}$ NMR data matched with previously described data. ${ }^{5 a}$

Synthesis of Pyrene Derivative $(P, 1 S, 2 S)$-2. A mixture of diol $(P, 1 S, 2 S)-1(50 \mathrm{mg}, 0.1 \mathrm{mmol})$ and $\mathrm{NaH}(32 \mathrm{mg}, 0.8 \mathrm{mmol}, 60 \%$ purity) in DMF ( $1 \mathrm{~mL}$ ) was stirred under an Ar atmosphere for $1 \mathrm{~h}$. Then, a solution of 1-chloromethylpyrene $(100 \mathrm{mg}, 0.4 \mathrm{mmol})$ in DMF $(2 \mathrm{~mL})$ was added, and the new mixture was stirred at room temperature and under an $\mathrm{Ar}$ atmosphere for $12 \mathrm{~h}$. Then, $\mathrm{CH}_{2} \mathrm{Cl}_{2}$ was added. The mixture was washed with $\mathrm{HCl}_{2} \mathrm{~N}$ and dried over anhydrous $\mathrm{Na}_{2} \mathrm{SO}_{4}$, and the solvent was removed. The residue was purified by flash chromatography (EtOAc/hexane 1:9) to give compound $(P, 1 S, 2 S)-2$ (54 mg, 58\%). White solid, mp 180-193 ${ }^{\circ} \mathrm{C} .{ }^{1} \mathrm{H}$ NMR $\left(500 \mathrm{MHz}, \mathrm{CDCl}_{3}\right): \delta 8.56(\mathrm{~d}, J=9.2 \mathrm{~Hz}, 1 \mathrm{H}), 8.27-8.21(\mathrm{~m}, 3 \mathrm{H})$, $8.18-8.13(\mathrm{~m}, 3 \mathrm{H}), 8.08-7.96(\mathrm{~m}, 2 \mathrm{H}), 7.62(\mathrm{~d}, J=7.5 \mathrm{~Hz}, 2 \mathrm{H}), 7.37$ $(\mathrm{td}, J=7.6,1.5 \mathrm{~Hz}, 1 \mathrm{H}), 7.31(\mathrm{td}, J=7.6,1.4 \mathrm{~Hz}, 1 \mathrm{H}), 6.80(\mathrm{~d}, J=7.5$ $\mathrm{Hz}, 2 \mathrm{H}), 5.67(\mathrm{~d}, J=12.4 \mathrm{~Hz}, 1 \mathrm{H}), 5.56-5.46(\mathrm{~m}, 2 \mathrm{H}), 5.32-5.21$ $(\mathrm{m}, 1 \mathrm{H}), 4.13-3.98(\mathrm{~m}, 1 \mathrm{H}), 3.93-3.78(\mathrm{~m}, 1 \mathrm{H}), 3.63$ (dd, $J=11.6$, $3.9 \mathrm{~Hz}, 1 \mathrm{H}) .{ }^{13} \mathrm{C} \mathrm{NMR}\left(125 \mathrm{MHz}, \mathrm{CDCl}_{3}\right): \delta 156.3(\mathrm{C}), 133.5(\mathrm{CH})$, $133.1(\mathrm{CH}), 132.7(\mathrm{CH}), 132.0(\mathrm{CH}), 131.4(\mathrm{C}), 131.0(\mathrm{C}), 130.8$ (C), $130.3(\mathrm{C}), 128.8(\mathrm{CH}), 128.3(\mathrm{CH}), 128.21(\mathrm{CH}), 128.19(\mathrm{CH})$, $127.6(\mathrm{CH}), 127.4(\mathrm{CH}), 126.3(\mathrm{CH}), 125.7(\mathrm{CH}), 125.5(\mathrm{C}), 125.2$ (C), $125.0(\mathrm{C}), 124.8(\mathrm{C}), 124.4(\mathrm{CH}), 124.0(\mathrm{CH}), 115.4(\mathrm{C}), 114.3$ $(\mathrm{CH}), 93.9(\mathrm{C}), 92.3(\mathrm{C}), 87.3(\mathrm{C}), 72.5\left(\mathrm{CH}_{2}\right), 70.9(\mathrm{CH}), 63.6$ $\left(\mathrm{CH}_{2}\right)$. HRMS (APCI-TOF) $m / z$ : $[\mathrm{M}]^{+}$calcd for $\mathrm{C}_{68} \mathrm{H}_{45} \mathrm{O}_{4}$, 925.3312; found, 925.3313.

Synthesis of Pyrene Derivative $(P, 1 S, 2 S)$-3. To a solution of $(P, 1 S, 2 S)-1(25 \mathrm{mg}, 0.05 \mathrm{mmol})$ in $\mathrm{CH}_{2} \mathrm{Cl}_{2}(5 \mathrm{~mL})$ were added DMAP (12 mg, $0.1 \mathrm{mmol})$, dicyclohexylcabodiimide (DCC) $(37 \mathrm{mg}$, $0.18 \mathrm{mmol}$ ), and 1-pyrenecarboxylic acid $(44 \mathrm{mg})$. The mixture was stirred at room temperature for $24 \mathrm{~h}$. Then, the solvent was removed. The residue was purified by flash chromatography (EtOAc/hexane $1: 9)$ to give compound $(P, 1 S, 2 S)-3(41 \mathrm{mg}, 87 \%)$. Yellow solid, $\mathrm{mp}$ 235-246 ${ }^{\circ} \mathrm{C} .{ }^{1} \mathrm{H}$ NMR $\left(400 \mathrm{MHz}, \mathrm{CD}_{2} \mathrm{Cl}_{2}\right): \delta 9.26(\mathrm{~d}, J=9.5 \mathrm{~Hz}$, $2 \mathrm{H}), 8.77(\mathrm{~d}, J=8.2 \mathrm{~Hz}, 2 \mathrm{H}), 8.26-8.19(\mathrm{~m}, 3 \mathrm{H}), 8.16(\mathrm{~d}, J=5.2 \mathrm{~Hz}$, $2 \mathrm{H}), 8.12$ (dd, $J=6.4,1.9 \mathrm{~Hz}, 4 \mathrm{H}), 8.07(\mathrm{~d}, J=5.1 \mathrm{~Hz}, 2 \mathrm{H}), 8.03$ (d, $J$ $=1.5 \mathrm{~Hz}, 2 \mathrm{H}), 8.01(\mathrm{~d}, J=2.9 \mathrm{~Hz}, 2 \mathrm{H}), 7.76-7.60(\mathrm{~m}, 4 \mathrm{H}), 7.44-$ $7.35(\mathrm{~m}, 8 \mathrm{H}), 6.78(\mathrm{~d}, J=8.6 \mathrm{~Hz}, 4 \mathrm{H}), 6.19(\mathrm{~d}, J=6.9 \mathrm{~Hz}, 2 \mathrm{H}), 4.80$ $(\mathrm{dd}, J=11.8,2.9 \mathrm{~Hz}, 2 \mathrm{H}), 4.52(\mathrm{dd}, J=11.4,7.8 \mathrm{~Hz}, 2 \mathrm{H}) .{ }^{13} \mathrm{C} \mathrm{NMR}$ $\left(100 \mathrm{MHz}, \mathrm{CD}_{2} \mathrm{Cl}_{2}\right.$ ): $\delta 167.5(\mathrm{C}), 157.8(\mathrm{C}), 135.3(\mathrm{C}), 134.1(\mathrm{CH})$, $134.0(\mathrm{CH}), 133.3(\mathrm{CH}), 131.9(\mathrm{C}), 131.5(\mathrm{C}), 130.7(\mathrm{C}), 130.4$ $(\mathrm{CH}), 130.2(\mathrm{CH}), 129.2(\mathrm{CH}), 128.9(\mathrm{CH}), 128.2(\mathrm{CH}), 127.6$ $(\mathrm{CH}), 127.1(\mathrm{CH}), 127.0(\mathrm{CH}), 126.9(\mathrm{CH}), 125.8(\mathrm{C}), 125.3(\mathrm{C})$, $125.2(\mathrm{C}), 125.0(\mathrm{CH}), 124.7(\mathrm{CH}), 124.4(\mathrm{C}), 122.8(\mathrm{C}), 116.4(\mathrm{C})$, $115.1(\mathrm{CH}), 94.4(\mathrm{C}), 92.8(\mathrm{C}), 87.8(\mathrm{C}), 69.1(\mathrm{CH}), 64.8\left(\mathrm{CH}_{2}\right)$. HRMS (APCI-TOF) $m / z$ : $[\mathrm{M}]^{+}$calcd for $\mathrm{C}_{68} \mathrm{H}_{41} \mathrm{O}_{6}, 953.2898$; found, 953.2893.

Steady-State and Time-Resolved Emission Spectroscopy. Steady-State Fluorescence Spectra Were Recorded Using a JASCO FP-8300 Spectrofluorometer in $10 \times 10 \mathrm{~mm}$ Cuvettes. Timeresolved fluorescence decay traces were collected via the timecorrelated single photon counting (TCSPC) method using a FluoTime 200 fluoromoter (PicoQuant, GmbH). The excitation source was a $375 \mathrm{~nm}$ pulsed diode laser (LDH-P-C-375B PicoQuant, $\mathrm{GmbH}$ ) using a $20 \mathrm{MHz}$ excitation frequency for measurements at 400 $\mathrm{nm}$ and $5 \mathrm{MHz}$ frequency for excimer measurements at $540 \mathrm{~nm}$. The full width at half-maximum (fwhm) of the laser pulses was around 40 ps. The fluorescence emission was collected at a $90^{\circ}$ geometry, focused 
at the detector after crossing through a polarizer (set at the magic angle), $2 \mathrm{~mm}$ slits, and a $2 \mathrm{~nm}$ bandwidth monochromator. TCSPC was achieved by a TimeHarp200 board, set at $36 \mathrm{ps} / \mathrm{channel}$. Fluorescence decay traces were collected for the necessary time to reach 20000 counts at the peak channel. For both compounds $(P, 1 S, 2 S)-2$ and $(P, 1 S, 2 S)-3$ decay traces were collected at 398, 400, and $402 \mathrm{~nm}$, where the maximum of emission was observed (corresponding to OPE and pyrene structures) and at 536, 538, and $540 \mathrm{~nm}$, where excimer emission is observed.

Time-resolved emission spectroscopy (TRES) of compounds $(P, 1 S, 2 S)-2$ and $(P, 1 S, 2 S)-3$ dissolved in $\mathrm{CH}_{2} \mathrm{Cl}_{2}$ was performed by collecting 66 fluorescence decay traces in the 390-650 nm emission range $\left(\Delta \lambda_{\mathrm{em}}=4 \mathrm{~nm}\right)$ at $5 \mathrm{MHz}$ excitation frequency during a fixed amount of time $(500 \mathrm{~s})$, to maintain the overall intensity information.

Circular Dichroism and Circularly Polarized Luminiscence Measurements. CD titrations were performed in an Olis DSM172 spectrophotometer with a xenon lamp of $150 \mathrm{~W}$ with a $1.0 \mathrm{~cm}$ pathlength quartz cell. In all of the cases, a fixed slit width of $1 \mathrm{~mm}$ and integration time of $0.2 \mathrm{~s}$ were selected. Titrations of compounds $(P, 1 S, 2 S)-2$ and $(P, 1 S, 2 S)-3$ were carried out by the addition of progressive quantities of a $2.5 \times 10^{-4} \mathrm{M}$ solution of $\mathrm{AgBF}_{4}$ salt, which was commercially available, to a $2.5 \times 10^{-5} \mathrm{M}$ solution of the corresponding compound in a 95:5 mixture of $\mathrm{CH}_{2} \mathrm{Cl}_{2}$ /acetone. To make the fitting of the kinetic constant easier, the concentration of ligands $(P, 1 S, 2 S)-2$ and $(P, 1 S, 2 S)-3$ was kept constant during the titration. To ensure this, a $2.5 \times 10^{-5} \mathrm{M}$ solution of these compounds was used as a solvent to prepare the $\mathrm{AgBF}_{4}$ solution.

Circularly polarized luminiscence (CPL) measurements were recorded in an Olis DSM172 spectrophotometer. The spectra were recorded at $1 \times 10^{-5} \mathrm{M}$ concentrations in HPLC grade solvents. A fixed wavelength LED $(372 \mathrm{~nm})$ as the excitation source was used.

\section{ASSOCIATED CONTENT}

\section{S Supporting Information}

The Supporting Information is available free of charge on the ACS Publications website at DOI: 10.1021/acs.joc.8b00162.

Experimental details on optical measurements, further details on theoretical calculations of computed structures, and spectral data (PDF)

\section{AUTHOR INFORMATION}

\section{Corresponding Authors}

*E-mail: dmalvarez@ugr.es.

*E-mail: jmcuerva@ugr.es.

\section{ORCID}

Sergio Abbate: 0000-0001-9359-1214

María Ribagorda: 0000-0001-7185-4095

Ángel Orte: 0000-0003-1905-4183

Giovanna Longhi: 0000-0002-0011-5946

Araceli G. Campaña: 0000-0001-5483-5642

Juan M. Cuerva: 0000-0001-6896-9617

\section{Notes}

The authors declare no competing financial interest.

\section{ACKNOWLEDGMENTS}

We thank the Ministerio de Economía y Competitividad (MINECO, Spain) (CTQ2017-85454-C2-1-P, CTQ201785454-C2-2-P, CTQ2015-70283-P, CTQ2014-53598-R), the European Research Council (ERC) (ERC-2015-STG-677023), and the "Unidad de Excelencia Quimica Aplicada a Biomedicina y Medioambiente" (UGR) for funding. A.G.C. and P.R also acknowledge funding from MINECO and MECD (Spain) for RyC-2013-12943 and FPU contracts, respectively. The Computing Center CINECA Via Magnanelli 6/3 40033,
Casalecchio di Reno (Bologna) Italy, is also acknowledged for access to computational facilities.

\section{REFERENCES}

(1) (a) Lindenburg, L.; Merkx, M. Sensors 2014, 14, 11691-11713. (b) Ruedas-Rama, M. J.; Hall, E. A. Nanotechnology 2014, 25, $195501-$ 195513.

(2) (a) Riehl, J. P.; Muller, G. Comprehensive Chiroptical Spectroscopy; Berova, N., Polavarapu, P. L., Nakanishi, K., Woody, R. W., Eds.; Wiley, 2012; Vol. 1. (b) Sanchez-Carnerero, E. M.; Agarrabeitia, A. R.; Moreno, F.; Maroto, B. L.; Muller, G.; Ortiz, M. J.; de la Moya, S. Chem. - Eur. J. 2015, 21, 13488-13500. (c) Castiglioni, E.; Abbate, S.; Lebon, F.; Longhi, G. Methods Appl. Fluoresc. 2014, 2, 024006. (d) Berova, N.; Di Bari, L.; Pescitelli, G. Chem. Soc. Rev. 2007, 36, 914-931. (e) Kumar, J.; Nakashima, T.; Kawai, T. J. Phys. Chem. Lett. 2015, 6, 3445-3452. (f) Longhi, G.; Castiglioni, E.; Koshoubu, J.; Mazzeo, G.; Abbate, S. Chirality 2016, 28, 696-707.

(3) For recent examples, see: (a) Gobo, Y.; Yamamura, M.; Nakamura, T.; Nabeshima, T. Org. Lett. 2016, 18, 2719-2721. (b) Nishimura, H.; Tanaka, K.; Morisaki, Y.; Chujo, Y.; Wakamiya, A.; Murata, Y. J. Org. Chem. 2017, 82, 5242-5249. (c) Takase, K.; Noguchi, K.; Nakano, K. Org. Lett. 2017, 19, 5082-5085. (c1) Kögel, J. F.; Kusaka, S.; Sakamoto, R.; Iwashima, T.; Tsuchiya, M.; Toyoda, R.; Matsuoka, R.; Tsukamoto, T.; Yuasa, J.; Kitagawa, Y.; Kawai, T.; Nishihara, H. Angew. Chem., Int. Ed. 2016, 55, 1377-1381. (d) Feuillastre, S.; Pauton, M.; Gao, L.; Desmarchelier, A.; Riives, A. J.; Prim, D.; Tondelier, D.; Geffroy, B.; Muller, G.; Clavier, G.; Pieters, G. J. Am. Chem. Soc. 2016, 138, 3990-3993. (e) Xiong, J.-B.; Feng, H.T.; Sun, J.-P.; Xie, W.-Z.; Yang, D.; Liu, M.; Zheng, Y.-S. J. Am. Chem. Soc. 2016, 138, 11469-11472. (f) Hellou, N.; Srebro-Hooper, M.; Favereau, L.; Zinna, F.; Caytan, E.; Toupet, L.; Dorcet, V.; Jean, M.; Vanthuyne, N.; Williams, J. A. G.; Di Bari, L.; Autschbach, J.; Crassous, J. Angew. Chem., Int. Ed. 2017, 56, 8236-8239. (g) Schulte, T. R. Holstein, J. J.; Krause, L.; Michel, R.; Stalke, D.; Sakuda, E.; Umakoshi, K.; Longhi, G.; Abbate, S.; Clever, G. H. J. Am. Chem. Soc. 2017, 139, 6863-6866. (h) Gon, M.; Morisaki, Y.; Chujo, Y. Chem. Commun. 2017, 53, 8304-8307. (i) Resa, S.; Miguel, D.; Guisán-Ceinos, S.; Mazzeo, G.; Choquesillo-Lazarte, D.; Abbate, S.; Crovetto, L.; Cárdenas, D. J.; Carreño, M. C.; Ribagorda, M.; Longhi, G.; Mota, A. J.; Álvarez de Cienfuegos, L.; Cuerva, J. M. Chem. - Eur. J. 2018, 24, 2653-2662.

(4) For example, see: (a) Maeda, H.; Bando, Y.; Shimomura, K.; Yamada, I.; Naito, M.; Nobusawa, K.; Tsumatori, H.; Kawai, T. J. Am. Chem. Soc. 2011, 133, 9266-9269. (b) Maeda, H.; Shirai, T.; Bando, Y.; Takaishi, K.; Uchiyama, M.; Muranaka, A.; Kawai, T.; Naito, M. Org. Lett. 2013, 15, 6006-6009. (c) Saleh, N.; Moore, B.; Srebro, M.; Vanthuyne, N.; Toupet, L.; Williams, J. A. G.; Roussel, C.; Deol, K. K.; Muller, G.; Autschbach, J.; Crassous, J. Chem. - Eur. J. 2015, 21, 16731681. (d) Hashimoto, Y.; Nakashima, T.; Shimizu, D.; Kawai, T. Chem. Commun. 2016, 52, 5171-5174. (e) Isla, H.; Srbo-Hooper, M.; Jean, M.; Vanthuyne, N.; Roisnel, T.; Lunkley, J. L.; Muller, G.; Willians, J. A. G.; Autschbach, J.; Crassous, J. Chem. Commun. 2016, 52, 59325935.

(5) (a) Morcillo, S. P.; Miguel, D.; Álvarez de Cienfuegos, L.; Justicia, J.; Abbate, S.; Castiglioni, E.; Bour, C.; Ribagorda, M.; Cárdenas, D. J.; Paredes, J. M.; Crovetto, L.; Choquesillo-Lazarte, D.; Mota, A. J.; Carreño, M. C.; Longhi, G.; Cuerva, J. M. Chem. Sci. 2016, 7, 56635670. (b) Fuentes, N.; Martin-Lasanta, A.; Alvarez de Cienfuegos, L.; Robles, R.; Choquesillo-Lazarte, D.; Garcia-Ruiz, J. M.; MartinezFernandez, L.; Corral, I.; Ribagorda, M.; Mota, A. J.; Cárdenas, D. J.; Carreño, M. C.; Cuerva, J. M. Angew. Chem., Int. Ed. 2012, 51, 1303613040.

(6) The corresponding enantiomers $(M, 1 R, 2 R)-2$ and $(M, 1 R, 2 R)-3$ were also prepared using ditosilate $(1 R, 2 R)-5$, showing mirror-image chiroptical properties. See the Supporting Information.

(7) Reiné, P.; Justicia, J.; Morcillo, S. P.; Mazzeo, G.; GarcíaFernández, E.; Rodríguez-Diéguez, A.; Álvarez de Cienfuegos, L.; Abbate, S.; Cuerva, J. M.; Longhi, G.; Miguel, D. Chirality 2018, 30, $43-54$. 
(8) (a) Kanaya, T.; Goshiki, K.; Yamamoto, M.; Nishijima, Y. J. Am. Chem. Soc. 1982, 104, 3580-3587. (b) Yamamoto, M.; Goshiki, K.; Kanaya, T.; Nishijima, Y. Chem. Phys. Lett. 1978, 56, 333-335. (c) Miguel, D.; Morcillo, S. P.; Martín-Lasanta, A.; Fuentes, N.; Martínez-Fernández, L.; Corral, I.; Ruedas-Rama, M. J.; Cárdenas, D. J.; Álvarez de Cienfuegos, L.; Orte, A.; Cuerva, J. M. Org. Lett. 2015, 17, 2844-2847.

(9) (a) Kano, K.; Matsumoto, H.; Hashimoto, S.; Sisido, M.; Imanishi, Y. J. Am. Chem. Soc. 1985, 107, 6117-6118. (b) Nakabayashi, K.; Amako, T.; Tajima, N.; Fujiki, M.; Imai, Y. Chem. Commun. 2014, 50, 13228-13230. (c) Amako, T.; Nakabayashi, K.; Suzuki, N.; Guo, S.; Rahim, N. A. A.; Harada, T.; Fujiki, M.; Imai, Y. Chem. Commun. 2015, 51, 8237-8240. (d) Nakabayashi, K.; Kitamura, S.; Suzuki, N.; Guo, S.; Fujiki, M.; Imai, Y. Eur. J. Org. Chem. 2016, 2016, 64-69. (e) Mimura, Y.; Nishikawa, T.; Fuchino, R.; Nakai, S.; Tajima, N.; Kitamatsu, M.; Fujiki, M.; Imai, Y. Org. Biomol. Chem. 2017, 15, 45484553. (f) Takaishi, K.; Takehana, R.; Ema, T. Chem. Commun. 2018, 54, 1449-1452.

(10) Martín-Lasanta, A.; Álvarez de Cienfuegos, L.; Johnson, A.; Miguel, D.; Mota, A. J.; Orte, A.; Ruedas-Rama, M. J.; Ribagorda, M.; Cárdenas, D. J.; Carreño, M. C.; Echavarren, A. M.; Cuerva, J. M. Chem. Sci. 2014, 5, 4582-4591.

(11) Unfortunately, we could not follow the binding process using NMR spectroscopy as in previous cases (refs 5a and 9) owing to the insolubility of $(P, 1 S, 2 S)-2$ and $(P, 1 S, 2 S)-3$ in the presence of $\mathrm{Ag}(\mathrm{I})$ cation at usual NMR concentrations.

(12) DynaFit program was used to study guest-host complexation equilibria: Gasa, T.; Spruell, J.; Dichtel, W.; Sorensen, T.; Philp, D.; Stoddart, J.; Kuzmič, P. Chem. - Eur. J. 2009, 15, 106-116.

(13) Some explanations about bisignated signals in CPL have been described: (a) Longhi, G.; Castiglioni, E.; Abbate, S.; Lebon, F.; Lightner, D. A. Chirality 2013, 25, 589-599. (b) Hall, J.; Renger, T.; Picorel, R; Krausz, E. Biochim. Biophys. Acta, Bioenerg. 2016, 1857, 115-128. (c) Duong, S. T.; Fujiki, M. Polym. Chem. 2017, 8, 46734679.

(14) Due to the complexity of the molecular system and also the limitation of the TD-DFT approximation, a calculation explaining the observed rotational strengths is beyond the scope of this work: Levine, B. G.; Ko, C.; Quenneville, J.; Martinez, T. J. Mol. Phys. 2006, 104, 1039-1051.

(15) The linear response is observed up to $3 \mathrm{Ag}(\mathrm{I})$ equivalents, taking into account that two fluorophores with different quantum yields must be recorded at the same time and the most intense peak determines the detector saturation and optimization process was carried out to minimize the spectral noise. Beyond such equivalents, the signals $(\Delta I)$ became too low that the errors in the measurement did not guarantee a reliable value of the ratio. With this limitation in the linear range, the resulted profile was exactly the expected one for a ratiometric probe.

(16) Although such apparatus is in its infancy, interesting real prototypes have been reported: (a) Tsumatori, H.; Harada, T.; Yuasa, J.; Hasegawa, Y.; Kawai, T. Appl. Phys. Express 2011, 4, 011601. (b) Frawley, A. T.; Pal, R.; Parker, D. Chem. Commun. 2016, 52, 13349-13352. 